\title{
ELECTROCHEMICAL AND ELECTROPHORETIC STUDY OF SODIUM METAMIZOLE
}

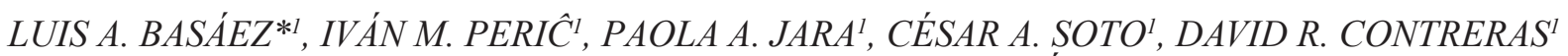 \\ CAROLINA AGUIRRE ${ }^{2}$ and PETR VANÝSEK
}

\author{
${ }^{1}$ Department of Analytical and Inorganic Chemistry, Faculty of Chemical Sciences, University of Concepción, Concepción, Chile \\ ${ }^{2}$ Faculty of Chemical Sciences, University of Santísima Concepción, Concepción, Chile \\ ${ }^{3}$ Department of Chemistry and Biochemistry, Northern Illinois University, DeKalb, IL 60115, USA \\ (Received: September 3, 2007 - Accepted: April 9, 2008)
}

\begin{abstract}
Electrochemical and electrophoretic behavior of sodium metamizole under conditions of variable $\mathrm{pH}$ has been studied. Voltammetric results indicate that sodium metamizole behaves as a quasi-reversible system over the potential window considered. These studies were complemented with capillary zone electrophoresis analysis in order to know the starting composition of solutions of sodium metamizole at different $\mathrm{pH}$ values and buffer composition. Among degradation products, the extent of the active metabolite 4-methylaminoantipyrine was found to be media dependent as well as was the appearance of different degradation products. Consequently, the extent of the oxidation process in voltammetric studies is dependent on the composition of the starting solutions. Information obtained by cyclic voltammetry and capillary zone electrophoresis has been concordant and conclusive in that both methods can be used in a qualitative study of sodium metamizole, under the experimental conditions assayed.
\end{abstract}

Keywords: sodium metamizole, NSAID, drugs, voltammetry, electrochemical determination, capillary zone electrophoresis.

\section{INTRODUCTION}

Pharmaceutical industry requires fast and reliable analytical methods in order to study intermediates as well as final products. The industry is always seeing new analytical techniques to obtain faster and more economical results and therefore there is always active and justified active research in this field. Dipyrone or sodium metamizole, [CA 68-89-3], sodium [(2,3-dihydro-1,5dimethyl-3-oxo-2-phenyl-1H-pyrazol-4-yl)methylamino] methanesulfonate (Fig. 1) is a well known water soluble white crystalline powder with an effective analgesic and antipyretic activity. Because of its possibly severe side effect, agranulocytosis, it is not available in the USA. However, it is very popular preparation in Europe and Latin America. Sodium metamizole is usually determined by spectrophotometry ${ }^{1-5}$, titrimetry ${ }^{6,7}$, amperometry ${ }^{8}$, fluorometry ${ }^{9,10}$, and high performance liquid chromatography (HPLC) ${ }^{11-13}$ Recently, chemiluminescence coupled with flow-injection analysis (FIA $)^{14,15}$, spectrophotometry coupled with FIA ${ }^{16,17}$, voltammetric ${ }^{18}$ and reflectometric ${ }^{19}$ determinations have been reported.

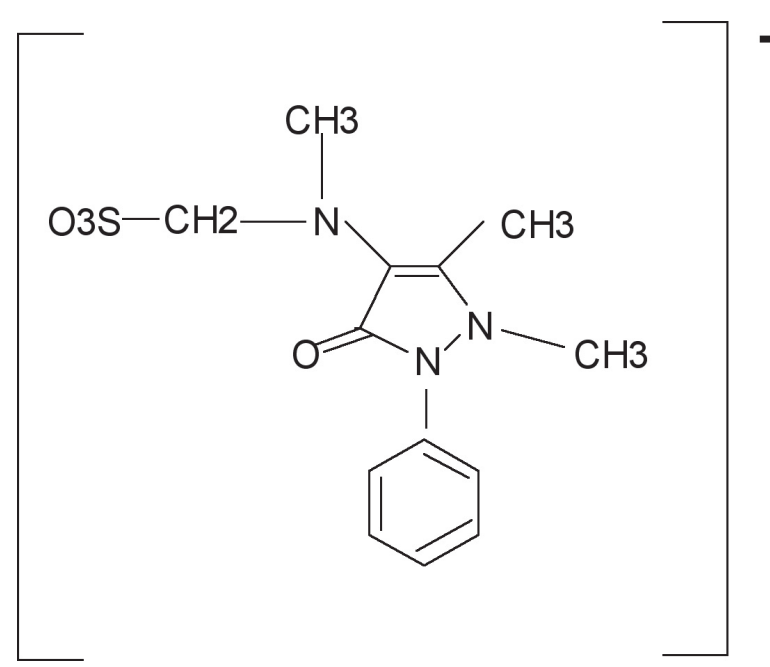

$\mathrm{Na}^{+}$

Figure 1. Chemical structure of Sodium Metamizole

Dipyrone is a non-opiate and non-steroidal anti-inflammatory analgesic drug (NSAID) which belongs to the group of pyrazolones ${ }^{20}$ It is actually a prodrug, which is effective only when it becomes hydrolyzed, after oral or intravenous intake, into its active metabolites ${ }^{21}$. In oral administration sodium metamizole spontaneously hydrolyzes in the gastric fluid by a non enzymatic mechanism to 4-methylaminoantipyrine, which is quickly and almost completely absorbed in the gastrointestinal tract. The 4-methylaminoantipyrine is metabolized in the liver by demethylation to 4-aminoantipyrine and by oxidation to 4-formylaminoantipyrine (inactive metabolite). 4-aminoantipyrine also converts by a polyformic acetylation to 4-acetylaminoantipyrin (inactive metabolite). It is necessary to point out that other non identified metabolites exists $^{22}$.

Dipyrone has been studied in vivo and in vitro by such techniques as HPLC and HPTC either as monodrug or in mixtures. Determination of 4-aminoantipyrine, dipyrone and its metabolites in urine and 4methylaminoantipyrine, 4-formylaminoantipyrine in plasma by micelar chromatography has been carried out ${ }^{23}$. HPLC has shown to be a technique of choice to be use in stability assays of pharmaceutical formulations of dipyrone (tablets and ampules) due to a good selectivity in reverse phase, detection limits and procedure speed ${ }^{24}$. Some of the degradation products have been detected and quantified by $\mathrm{TLC}^{25}$. Favorable repeatability and detection limits make this technique favorable for dipyrone stability assays in tablets and ampoules ${ }^{24}$. High performance thin layer chromatography (HPTLC) has been used to quantify sodium metamizole in suppositories at it has been shown that this method did not produce results significantly different from the official spectrophotometric method prescribed for its quantification by the German Pharmacopoeia ${ }^{26}$.

Dipyrone is often determined in pharmaceutical formulations with caffeine, paracetamol, or codeine using successfully spectroscopy ${ }^{27}$. Preparation with ascorbic acid was successfully accomplished electrochemically by polarographic determination ${ }^{28}$.

Dipyrone itself is not particularly stable and therefore routine assays must be performed quite regularly. Dipyrone has good stability when stored under completely anhydrous conditions and at low atmospheric pressure. In liquid formulations, an increased stability could be obtained by blanketing with an inert gas and by addition of a suitable antioxidant ${ }^{29}$.

We and others have reported earlier electrochemical techniques in which drug assay is performed by means of the transport across the interface between two immiscible electrolytes (ITIES). For example betalactamic antibiotics like ampicillin and cephalexin ${ }^{30}$ and amoxicillin ${ }^{31}$ were studied by this method. ITIES studies of the degradation products for acid and alkaline hydrolysis of penicillin $\mathrm{V}$, amoxicillin in pure drugs as well as in pharmaceutical formulations, showed that the obtained results are comparable to the standard HPLC methods (XXII USP) and statistical evaluation showed no significant differences between the two methods. Voltammetric methods can be used for simple and fast determinations for some drugs such as gestodene, insulin and dopamine in presence of ascorbic acid ${ }^{32}$.

In this study we will use a variant of the cyclic voltammetry where the applied potential generates a potentiodynamic perturbation between two preset limits inside the potential window of the solvent ${ }^{33}$. Cyclic voltammetry, a type of potentiodynamic electrochemical measurement where a potential is applied to the system ${ }^{34,35}$, and the faradaic current response is measured is not alone very suitable analytical method for drug determination because it lacks the needed specificity.

On the other hand, capillary electrophoresis (CE) separation has been used frequently in the development and validation of a method for separation and 
determination of components in different pharmaceutical formulations. If all the components of interest are in ionic form, then capillary zone electrophoresis (CZE) can be chosen as the better electrophoretic mode with by Capillary Electrophoresis Analysis Combined with Infra-red Spectroscopy ${ }^{36.37}$. The high resolution and efficiency that can be achieved allow to apply this method not only for the determination of the active substance but also for stability control of pharmaceutical formulations. To the best of our knowledge, there are no communications on the use of capillary zone electrophoresis for the analysis of sodium metamizole in pure drug as well as pharmaceutical formulations. The main attractiveness of $\mathrm{CE}$ is that it uses small quantities of sample and reagents, it is fast, and also very versatile in separating analytes of small and large molecular mass, both neutral and charged.

\section{EXPERIMENTAL}

\section{Apparatus}

Cyclic voltammetric measurements were carried out with the Voltammetry Analyzer BAS CV-50W in a classic cell equipped with three electrodes platinum working, platinum auxiliary (area $5 \mathrm{~cm}^{2}$, approximately 10 times larger than the working electrode) and an $\mathrm{Ag} / \mathrm{AgCl}$ reference electrodes. The capillary electrophoresis separations were performed on a PrinCE 450 capillary electrophoresis system (Prince Technologies, Essen, Netherlands) equipped with a Lambda 1010 UV-VIS detector (Bishoff, Leonberg, Germany). Fused silica capillaries (Polymicro Technology, Phoenix, AZ, USA) of $50 \mu \mathrm{m}$ i.d. and $45 / 55 \mathrm{~cm}$ were used. The system DAx v. 5.0 software was used for data acquisition.

\section{Reagents and solutions}

All the solutions were prepared with ASTM type 1 reagent grade water obtained by passing deionized water though an E-Pure ${ }^{\mathrm{TM}}$ 4-holder water purification system (Barnstead Thermolyne Corp., Dubuque, USA). All chemicals were of analytical grade and used without further purification. The supporting electrolytes used for experiments were a $0.10 \mathrm{~mol} \mathrm{~L}^{-1} \mathrm{KNO}_{3}$ or $\mathrm{HNO}_{3}$. Different buffers solutions were prepared in the range of $\mathrm{pH}$ from 1 up to $11 . \mathrm{Na}_{2} \mathrm{HPO}_{4} / \mathrm{NaH}_{2} \mathrm{PO}_{4}$ and $\mathrm{NaH}_{2} \mathrm{PO}_{4} / \mathrm{H}_{3} \mathrm{PO}_{4}$ systems for $\mathrm{pH} 1,2,3,6$ and 7 . $\mathrm{NaAc} / \mathrm{HAc}$ system for $\mathrm{pH} 4$ and 5 ; and $\mathrm{Na}_{2} \mathrm{CO}_{3} / \mathrm{NaHCO}_{3}$ system for $\mathrm{pH} 8,9,10$ and 11. A $0.10 \mathrm{~mol} \mathrm{~L}^{-1} \mathrm{NaOH}$ or $\mathrm{HCl}$ were used to adjust the $\mathrm{pH}$ of the buffer solutions. A $0.010 \mathrm{~mol} \mathrm{~L}^{-1}$ sodium metamizole (Industrial Kern, Spain; a gift from Laboratorio Pasteur, Chile) was prepared by dissolution of an appropriate amount of this reagent in a supporting electrolyte or buffer solution and used for voltammetric measurements. Capillary electrophoresis determinations were carried out with $0.050 \mathrm{~mol} \mathrm{~L}^{-1}$ sodium metamizole samples obtained by further dilution of the $0.010 \mathrm{~mol} \mathrm{~L}^{-1}$ solution, prepared as before, with the required supporting electrolyte or buffer solution. The running buffer consisted of 0.050 mol L ${ }^{-1}$ boric acid adjusted to $\mathrm{pH} 9.2$ with $0.01 \mathrm{~mol} \mathrm{~L}^{-1} \mathrm{NaOH}$. All solutions were filtered through a $0.45 \mu \mathrm{m}$ syringe filter and degassed by sonication for 5 minutes before injection to the CE system.

\section{Procedure}

Before the voltammetric measurements, the $0.010 \mathrm{~mol} \mathrm{~L}^{-1}$ sodium metamizole solution was purged with nitrogen for 20 minutes to remove dissolved oxygen. The cell was thermostated at $20^{\circ} \mathrm{C}$. The working electrode was polished with alumina (BAS CF-1050) on an alumina polishing pad (BAS MF-1040) for $2 \mathrm{~min}$ and then rinsed with Type 1 reagent grade water before each measurement. The voltammetric experiments were performed in stirred solutions.

In the CE experiments the capillary was routinely rinsed with $0.10 \mathrm{~mol}$ $\mathrm{L}^{-1} \mathrm{NaOH}(15-20 \mathrm{~min})$, water $(10 \mathrm{~min})$ and running buffer $(10 \mathrm{~min})$ at the beginning of each working day. The samples were injected hydrodynamically at pressure $5000 \mathrm{~Pa}$ for $6 \mathrm{~s}$. The running voltage was $18 \mathrm{kV}$ and the temperature was set at $25 \mathrm{C}$. UV detector was used with detection wavelength $200 \mathrm{~nm}$. Between individual runs the capillary was rinsed with $0.10 \mathrm{~mol} \mathrm{~L}^{-1} \mathrm{NaOH}(10$ $\mathrm{min}$ ), water (5 $\mathrm{min}$ ) and running buffer $(5 \mathrm{~min})$.

\section{RESULTS AND DISCUSSION}

The effect of the scan rate variation from 1 to $100 \mathrm{mV} \mathrm{s}^{-1}$ on the cyclic voltammetry response behavior was investigated. $10 \mathrm{mmol} \mathrm{L}^{-1}$ sodium metamizole analyte in $100 \mathrm{mmol} \mathrm{L}^{-1} \mathrm{KNO}_{3}$ or $\mathrm{HNO}_{3}$ polarized in the range of from +0.30 to $+0.75 \mathrm{~V}$ on right platinum electrode was used. Sodium metamizole shows a distinct anodic peak. The current of this peak varied linearly with the scan rate when $\mathrm{KNO}_{3}$ was used as the supporting electrolyte.
Based on these results (not shown), a scan rate of $100 \mathrm{mV} \mathrm{s}^{-1}$ was chosen for further studies as it provided voltammograms with acceptable peak resolution.

The effect of $\mathrm{pH}$ on the voltammetry of the $0.010 \mathrm{~mol} \mathrm{~L}^{-1}$ sodium metamizole solution at a platinum working electrode was also studied. Cyclic voltammograms at $\mathrm{pH} 2$ and $\mathrm{pH} 3$ (Figs. 2 and 3) indicates a clear evidence of a redox reaction, with an incipient sign of oxidation in the $\mathrm{Na}_{2} \mathrm{HPO} / \mathrm{NaH}_{2} \mathrm{PO}_{4}$ buffer. These results are in agreement with the corresponding electropherograms (Figs. 6 and 7) which show that hydrolysis at $\mathrm{pH} 2$ was greater than at $\mathrm{pH}$ 3 when the samples were prepared. The greater the extent of hydrolysis, the smaller is the oxidation peak in the corresponding voltammogram.

The behavior of the sodium metamizole in acidic media does not have notable interference on the working electrode, possibly because the electrode is not sensitive enough to capture differences in the structure of the drug and degradation products. However, dynamics apparently plays an important role in the behavior of this analyte as is corroborated by the presence of a quasireversible behavior clearly manifested by the $\mathrm{E}_{\mathrm{pa}}-\mathrm{E}_{\mathrm{pc}}$ differences close to 0.1 $\mathrm{V} v$ s. $\mathrm{Ag} / \mathrm{AgCl}$.

Systems at higher $\mathrm{pH}$ values become more irreversible (Figs. 4 and 5), which could be due to the appearance of different degradation products shown at the corresponding electropherograms (Fig. 8 and 9) in $\mathrm{Na}_{2} \mathrm{CO}_{3} / \mathrm{NaHCO}_{3}$ buffer. The appearance of the active metabolite 4-methylaminoantipyrine is clearly shown by the presence of a peak at the left side of the electropherogram. Sodium metamizole itself is the peak at the right side of the electropherograms. Consequently, the peaks in between can be attributed to unidentified degradation products.

The effect of the media matrix is also remarkable, since at $\mathrm{pH} 8$ in the $\mathrm{Na}_{2} \mathrm{CO}_{3} / \mathrm{NaHCO}_{3}$ buffer the amount of 4-methylaminoantipyrine is small and the extent of the degradation product eluted close to sodium metamizole is important (Fig. 8), but the amount of 4-methylaminoantipyrine becomes significant at $\mathrm{pH} 11$ as well as does the appearance of a new degradation product observed between sodium metamizole and 4-methylaminoantipyrine, a peak which is almost imperceptible at $\mathrm{pH} 8$ (Fig. 9). On the contrary, Fig. 6 $(\mathrm{pH} 2)$ shows an important degradation product close to sodium metamizole, which is almost negligible in Fig. $7(\mathrm{pH} 3)$, all this is when the same $\mathrm{Na}_{2} \mathrm{HPO}_{4} /$ $\mathrm{NaH}_{2} \mathrm{PO}_{4}$ buffer was used, at $\mathrm{pH} 2$ and $\mathrm{pH} 3$ respectively.

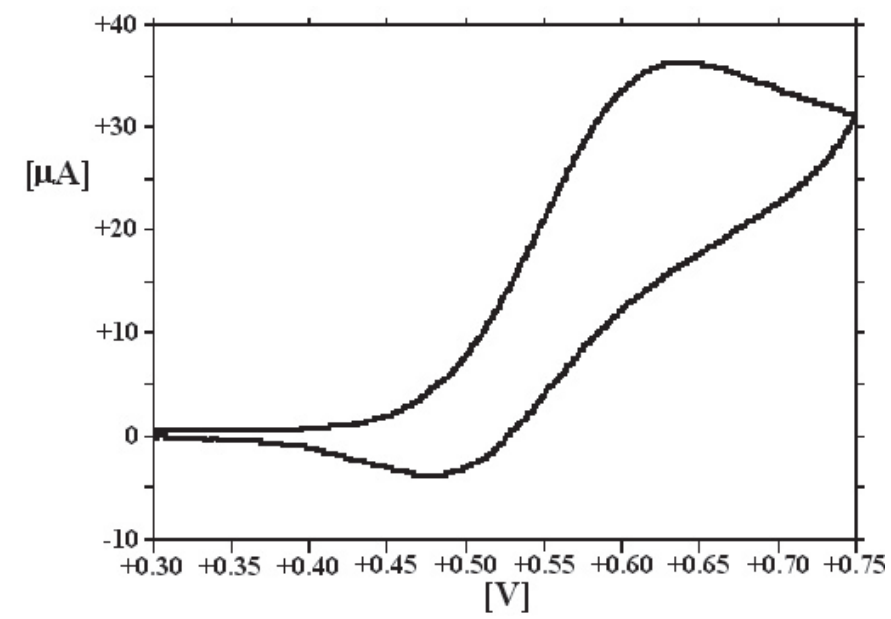

Figure 2. Voltammogram of sodium metamizole in a buffered solution at $\mathrm{pH} 2$ 


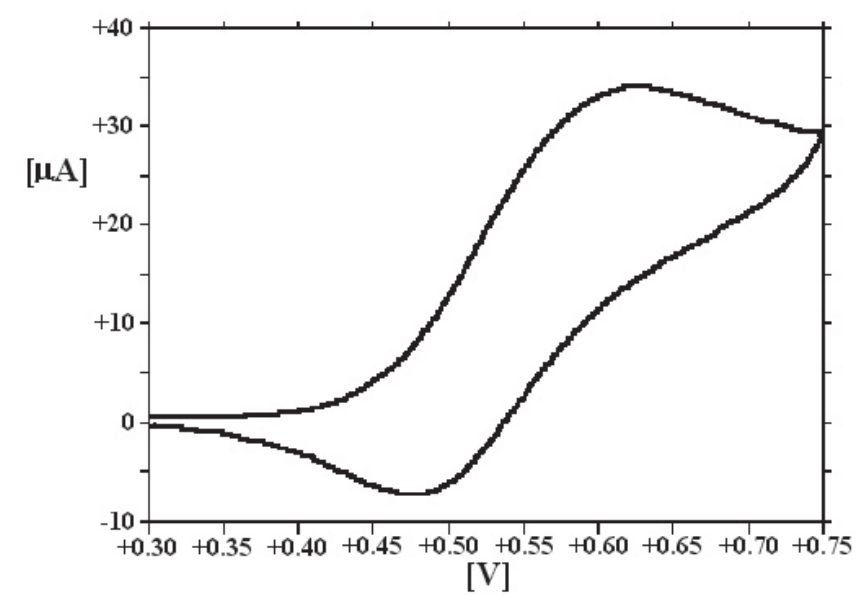

Figure 3. Voltammogram of sodium metamizole in a buffered solution at $\mathrm{pH} 3$

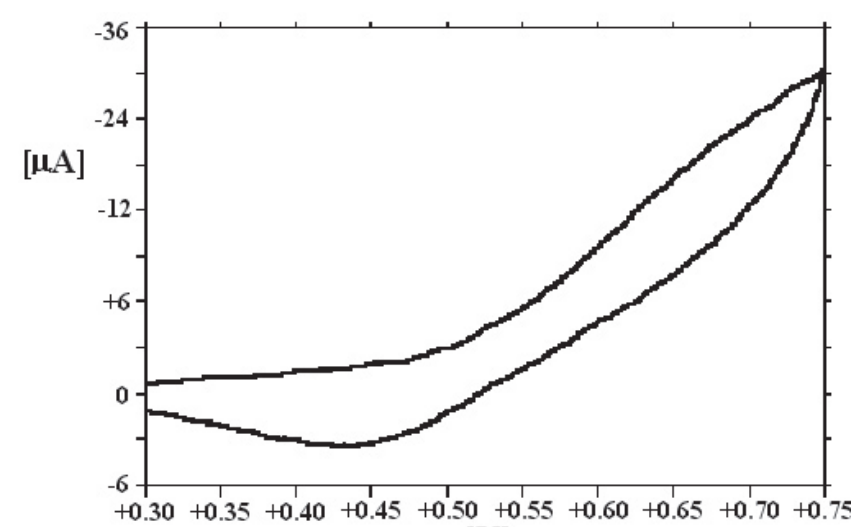

[V]

Figure 4. Voltammogram of sodium metamizole in a buffered solution at $\mathrm{pH} 8$

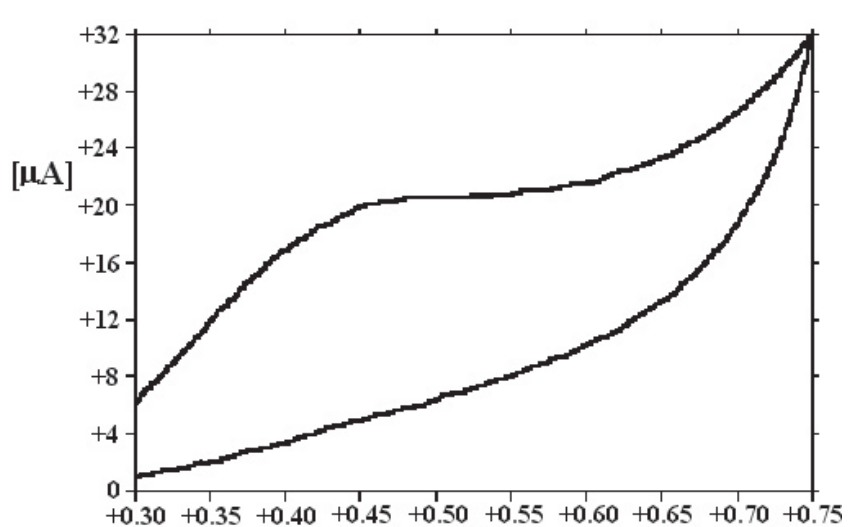

[V]

Figure 5. Voltammogram of sodium metamizole in a buffered solution at $\mathrm{pH} 11$

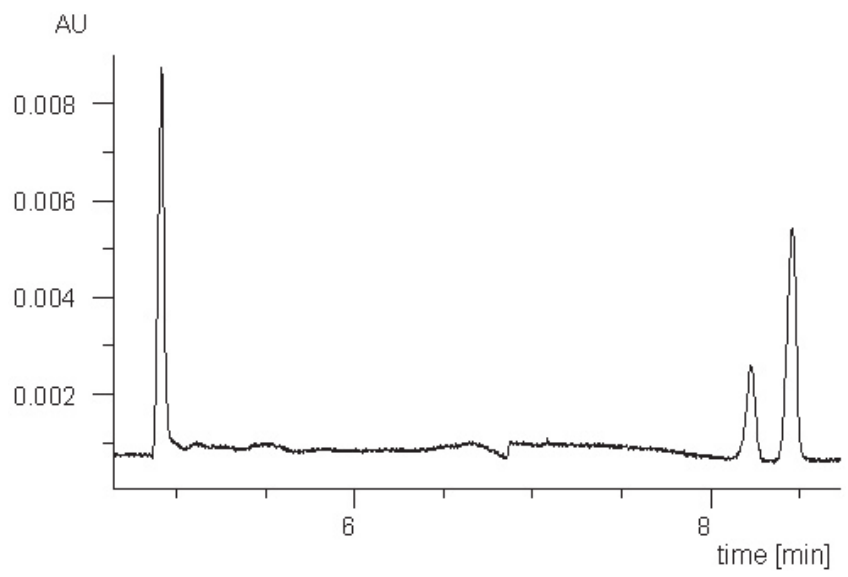

Figure 6. Electropherogram of sodium metamizole in a buffered solution at $\mathrm{pH} 2$

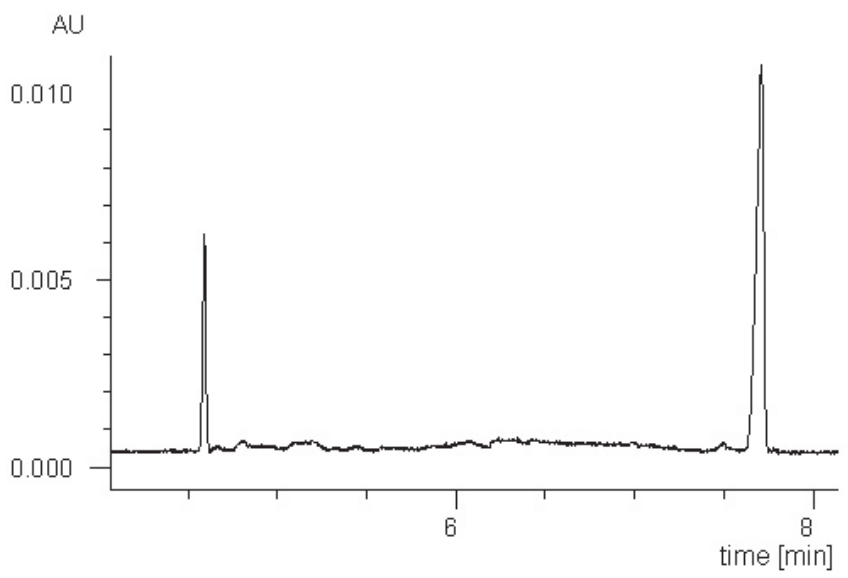

Figure 7. Electropherogram of sodium metamizole in a buffered solution at $\mathrm{pH} 3$

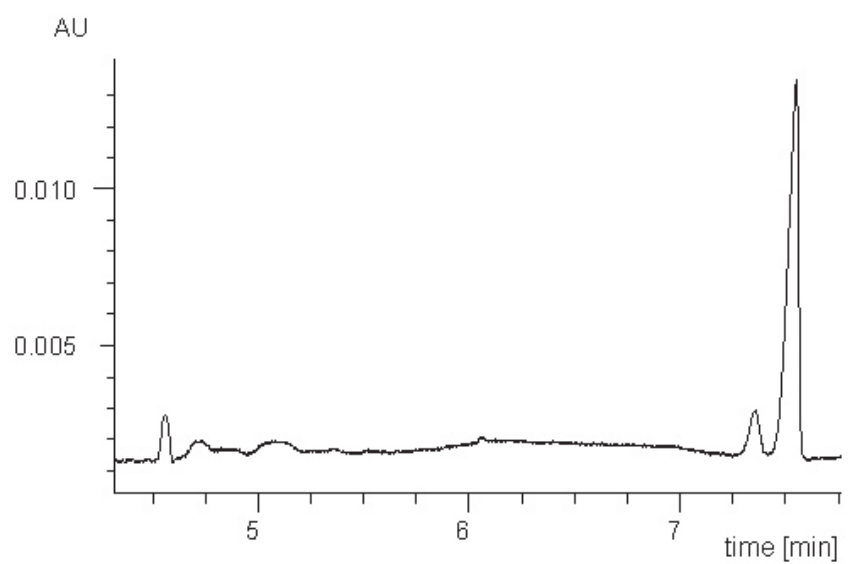

Figure 8. Electropherogram of sodium metamizole in a buffered solution at $\mathrm{pH} 8$ 


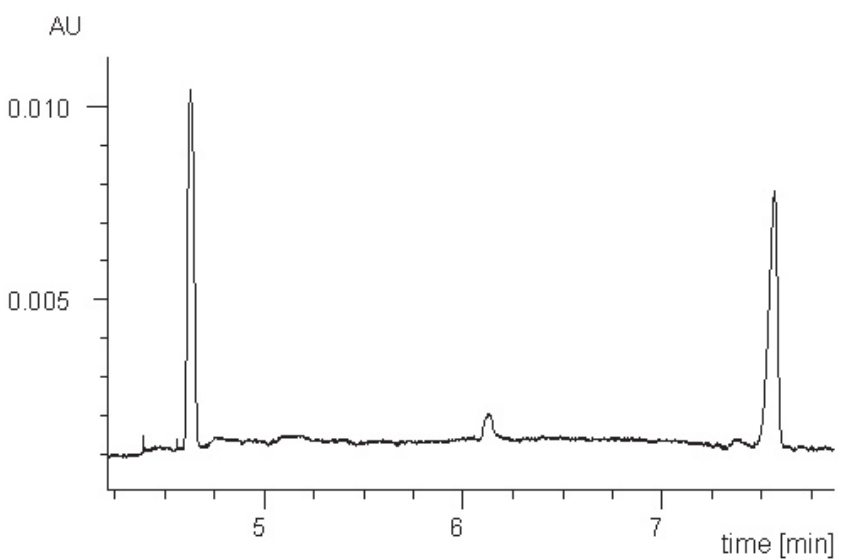

Figure 9. Electropherogram of sodium metamizole in a buffered solution at $\mathrm{pH} 11$

\section{CONCLUSIONS}

Cyclic voltammetry and capillary zone electrophoresis have been assessed for the development of analytical methodologies for sodium metamizole as possible alternative to the quality control needs of the pharmaceutical industry. The information obtained by either the cyclic voltammetry or the capillary zone electrophoresis is concordant and lead to the conclusion that both methods can be used in the qualitative study of sodium metamizole. Voltammetric results indicate that sodium metamizole behaves as a quasi-reversible redox system within the potential window where it was investigated.

In acidic media the voltammograms show higher anodic but lower cathodic currents. This is explained a consequence of the fact that in the acidic medium an oxidation of the drug occurs and instead its oxidation product in now detected. The extent of this oxidation process is determined by the composition of the starting samples, the different $\mathrm{pH}$ values as well as the buffer composition, all of which was established from the results of the capillary zone electrophoresis experiments. The corresponding electropherograms show peaks attributable to sodium metamizole, 4-methylaminoantipyrine and some additional degradation products, which are generated depending on $\mathrm{pH}$ and buffer composition.

The drug and its degradation products give voltammetric signatures. However, the chemical nature of the degradation products was not identified in this study.

\section{ACKNOWLEDGEMENTS}

The authors thank the financial support from the Dirección de Investigación of the Universidad de Concepción, DIUC (Grants N $N^{\circ} 03.021 .017-1.0$, $\mathrm{N}^{\circ} 207.021 .025-1.0$ and 208.021.025-1.0).

\section{REFERENCES}

1 N. Erk, F. Onur. Anal. Lett. 30, 1201 (1997).

2 N. Erk, F. Onur. Anal. Lett. 30, 1503 (1997).

3 S. Z. Qureshi, A. Saeed, T. Hasan. Talanta. 36, 861 (1989).

4 H. N. Doğan, Pharmazie. 51, 773 (1996).

5 T. Aburjai, B. L. Amro, K. Aiedeh, M. Abuirjeje, S. Al-Khalil. Pharmazie.

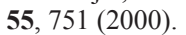

6 M. K. Srivastava, S. Ahmad, D. Singh, I. C. Shukla, Analyst. 110, 735 (1985).

7 M. M. Amer, B. A. El-Zeany, A. M. Taha, O. A. El-Saewy. Analyst. 107, 1272 (1982).

8 T. Pérez Ruiz, C. Martínez Lozano, V. Tomas, J. Carpena. J. Pharm. Biomed. Anal., 12, 1109 (1994).

9 T. Pérez Ruiz, C. Martínez Lozano, V. Tomas, J. Carpena. Microchem. J. 47, 296 (1993).

10 M. S. Di Nezio, M. F. Pistonesi, M. E. Centurion, M. E. Palomeque, A. G.. Lista, F. S. F. Band. J. Braz. Chem. Soc. 18, 1439 (2007).

11 H. L. Rau, A. R. Arror, P. Gundu Rao. Indian Drugs. 29, 92 (1991).

12 H. M. Stevens, R. Gill, J. Chromatogr. A. 370, 39 (1986).

13 H. Z. Senyuva, I. Aksahin, S. Ozcan, B. V. Kabasakal. Anal. Chim. Acta. 547, 73 (2005).

14 Y.-M. Huang, C. Zhang, X.-R. Zhang, Z.-J. Zhang. Fresenius J. Anal.
Chem. 365, 381 (1999).

15 J. F. C. Lima, S. M. O. Sá, J. M. Santos, E. A. G. Zagatto. J. Pharm. Biomed. Anal. 32, 1011 (2003).

16 L. H. Marcolino-Junior, R. A. Sousa, O. Fatibello-Filho, F. C. Moraes, M. F. S. Teixeira, Anal. Lett. 38, 2315 (2005).

17 P. L. Weinert, J. R. Fernandes, L. Pezza, H. R. Pezza. Anal. Sci. 23, 1383 (2007).

18 M. F. S. Teixeira, L. H. Marcolino-Jr., O. Fatibello-Filho, E. R. Dockal, É. T. G. Cavalheiro. J. Braz. Chem. Soc. 15, 803 (2004).

19 P. L. Weinert, L. Pezza, H. R. Pezza. J. Braz. Chem. Soc. 18, 846 (2007).

20 B. Anibarro, J. L. Fontela. Ann. Allergy Asthma Immunol. 78, 345 (1997).

21 C. Foulon, M.-C. Menet, C. Pham-Huy, P. Sandouk, J.-M. Scherrmann, H. Galons, F. Guyon, J.-R. Claude. Toxicol. Lett. Suppl 1. 95, 121 (1998).

22 H. Fabre, K. D. Altria. LC-GC Europe. 14, 302 (2001).

23 L. Escuder-Gilabert, J. J. Martínez-Pla, S. Sagrado, R. M. VillanuevaCamañas, M. J. Medina-Hernández. J. Chrom. B. 797, 21 (2003).

24 S. H. L. Thomas. J. Toxicol. Clin. Toxicol. 41, 383 (2003).

25 L. T. Ou, W. Jing, J. E. Thomas. J. Ind. Microbiol. Biotechnol. 14, 312 (1995).

26 S. Hess, M. Akermann, D. Ropte, K. Eger, J. Pharm. Biomed. Anal. 25, 531 (2001).

27 B. L. Fiebich, K. Lieb, M. Hüll, B. Aicher, J. van Ryn, M. Pairet, G. Engelhardt, Neuropharmacology. 39, 2205 (2000).

28 F. Belal. Electroanalysis. 4, 589 (1992).

29 H. Abdine, S. A. Soliman, M. G. Morcos. J. Pharm. Sci., 62, 1834 (2006).

30 L. Basáez, P. Vanýsek. J. Pharmaceut. Biomed., 19, 183 (1999).

31 L. Basáez, I. Perič, C. Aguirre, P. Vanýsek. J. Chil. Chem. Soc. 46, 203 (2001).

32 S. P. Wilson and N. Kirshner. J.Neurosci. 3, 1971 (1983).

33 N. Spano, A. Panzanelli, P. Costantina, M. I. Pilo, G. Sanna, R. Seeber, A. Tapparo. Anal. Chim. Acta. 553, 201 (2005).

34 L. Basáez, B. Rivas, F. Brovelli. J. Chil. Chem. Soc., 48, 135 (2003).

35 A. Arrieta, A. Almario, R. R. Vieira. J. Chil. Chem. Soc. 51, 971 (2006).

36 I. Perič, B. Rivas, A. Pooley, E. Riffo, L. Basáez. J. Chil. Chem. Soc. 44, 345 (1999).

37 X. Qian, N. Gang, W. Xian-hua and C. Gang. Chem. Res. Chinese U. 23, 6654 (2007). 